\title{
The Effect of Teaching Clinical Reasoning on Critical Thinking of Undergraduate Nursing Students Taking the Course of Emergency Nursing in Disasters and Events: A Preliminary Study
}

\author{
Kameli. $\mathrm{S}^{1}$ \\ ${ }^{*}$ Aliyari. Sh${ }^{2}$ \\ Habibi. $\mathrm{H}^{3}$ \\ Pishgooie. SAH ${ }^{4}$ \\ 1- MSc Student in Emergency \\ Nursing, Faculty of Nursing, \\ Aja University of Medical \\ Sciences, Tehran, Iran. \\ 2- ( ${ }^{*}$ Corresponding Author) \\ Ph.D. in Curriculum Studies, \\ Assistant Professor, Maternal \\ Newborn Health Department, \\ Aja University of Medical \\ Sciences, Faculty of Nursing. \\ Email: sh.aliyari@ajaums.ac.ir \\ 3- MSc Nursing, Instructor, \\ Pediatric Department, Faculty \\ of Nursing, Aja University of \\ Medical Sciences, Tehran, \\ Iran. \\ 4- Ph.D., of Nursing, Assistant \\ Professor, Critical care \\ Nursing Department, Faculty \\ of Nursing, Aja University of \\ Medical Sciences, Tehran, \\ Iran.
}

\begin{abstract}
Introduction: In the education of medical sciences- e g, nursing, the main goal is to train students who can make the best decisions with high thinking skills (critical thinking), integrating information, and using sound clinical reasoning while relying on evidence.
\end{abstract}

Objectives: The current study aimed at investigating the effect of teaching clinical reasoning on the critical thinking skill of undergraduate nursing students who took the course of emergency nursing in disasters and events.

Materials and Methods: The current quasi-experimental study was conducted on 27 undergraduate students of the 6th semester in Aja Nursing Faculty enrolled in a full-scale study in 2018. The critical thinking styles of students were assessed using the California critical thinking questionnaire before and two weeks after training. The clinical reasoning training program was presented using a repeat hypothesis model in five educational sessions. Data were analyzed by SPSS software version 23 using paired samples t-test.

Results: In the present study, the mean and standard deviation scores of critical thinking were respectively $7.63 \pm 2.02$ and $7.9 \pm 3.36$ before and after the training program. There was a significant difference between before and after mean scores of critical thinking education $(\mathrm{P}=0.047)$; training with clinical reasoning method improved the critical thinking skills compared to the study onset in the students.

Discussion and Conclusion: The critical thinking level of nursing students increased significantly after receiving educations with the method of clinical reasoning compared to the study onset level. It can be concluded that this educational method, like other active teaching methods, can improve critical thinking in nursing students. It is hoped that using this method will be an effective step toward better learning of the students and improving the performance of nurses in clinical practice.

Keywords: Critical Thinking, Clinical Reasoning, Teaching Methods, Nursing Students. 


\title{
بررسى تأثير آموزش استدلال بالينى بر تفكر انتقادى دانشجويان كارشناسى يرستارى در درس يرستارى اورخانس در بحرانها و حوادث غير مترقبه: يك مطالعه مقدماتى
}

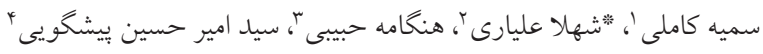

جكکبه

مقدمه: در آموزش علوم يزشكى از جمله يرستارى هدف تربيت افرادى است كه بتوانند با مهارتهاى تفكر عالى (تفكر

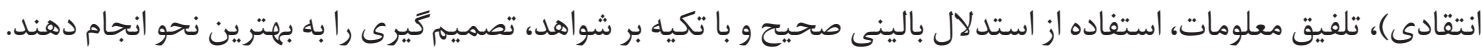

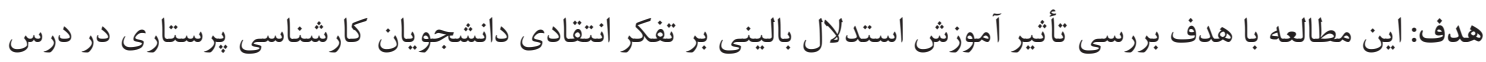
يرستارى اورزانس در بحرانها و حوادث غير مترقبه، انجام شد.

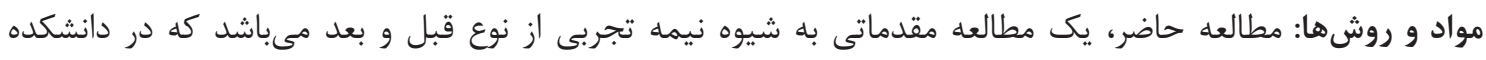

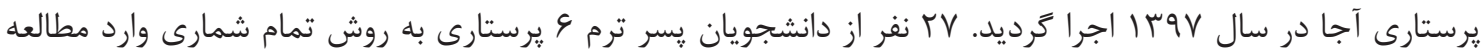

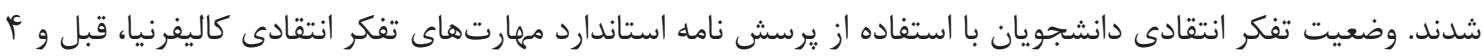

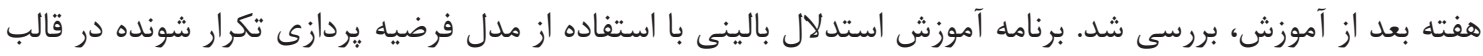

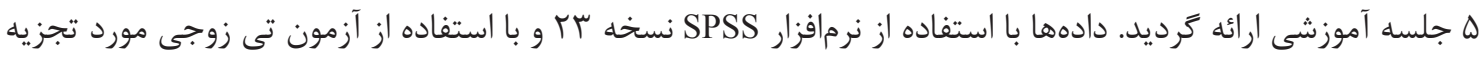
و تحليل قرار ترفت.

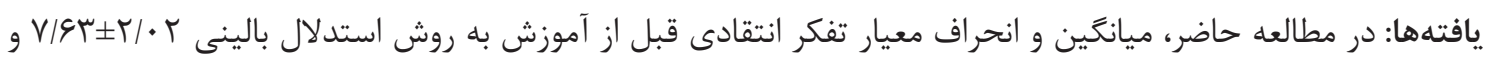

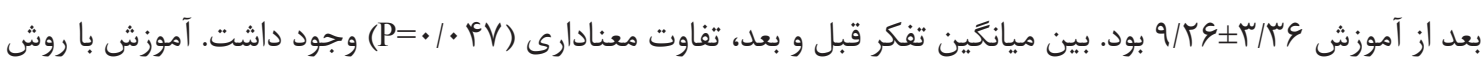

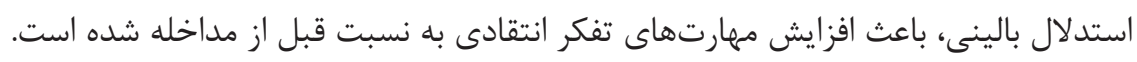

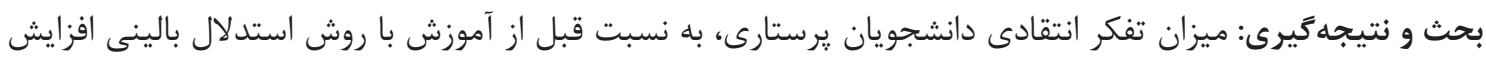

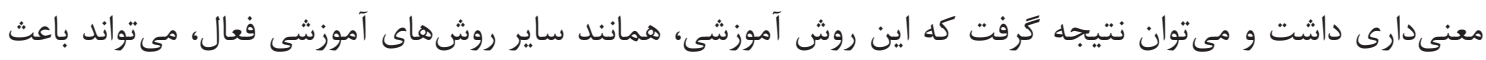

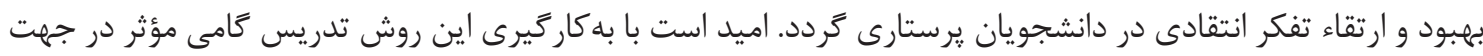

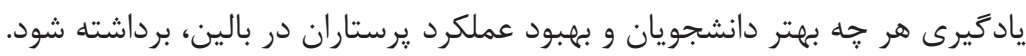

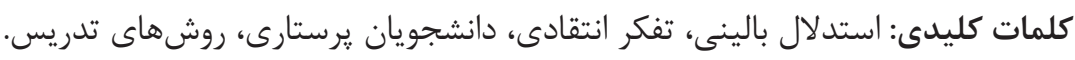

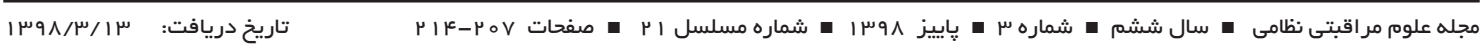
تاريخ يذيرش: تاريخ دريافت:

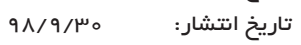

دقت و هوشيارى زيادى دارد و هر گَونه كمبود و نارسايى در آموزش مقدمه

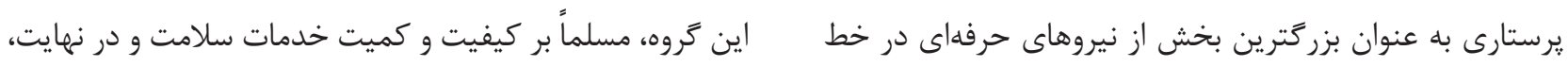

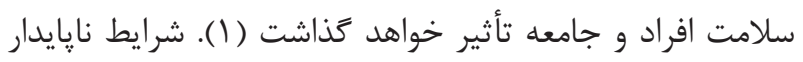

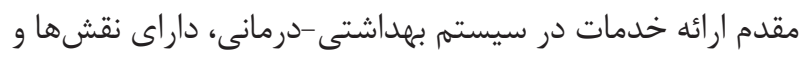

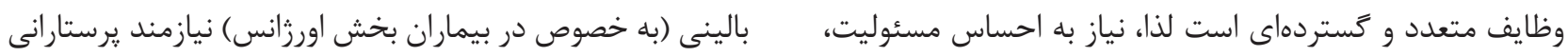


تحليلى و مبتكرانه را به كار مىبندند. از اين رو، آموزش استدلال

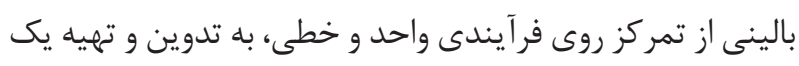

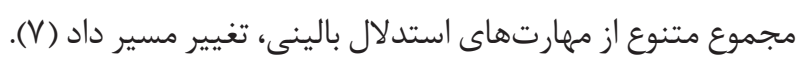

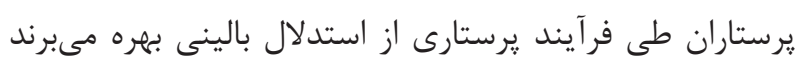

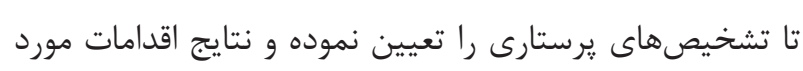

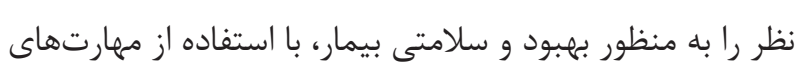

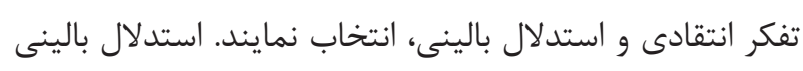

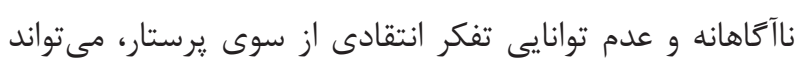

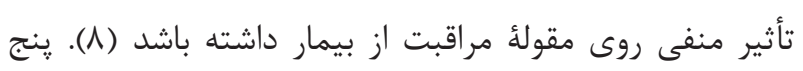

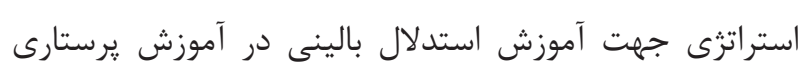

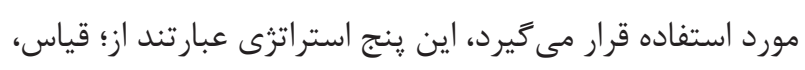

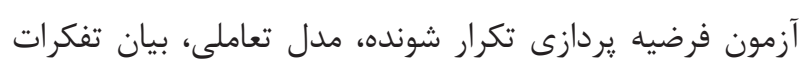

(Thinking aloud)

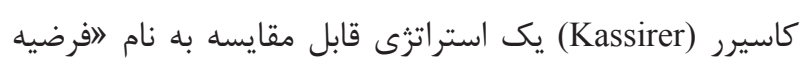
يردازى تكرار شونده" را براى بهبود و ارتقاء استدلال بالينى ارائه

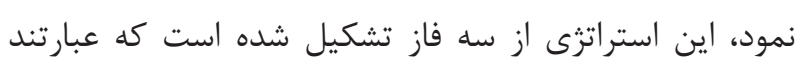

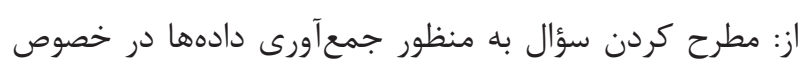

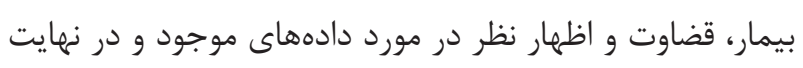
تفسير دادهاى مذكور با هدف تشريح و توصيف تأثير اطلاعات

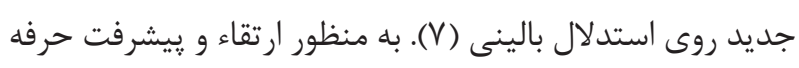

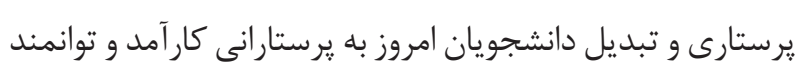

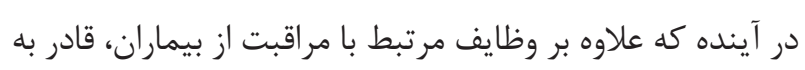
انجام فعاليتهاى مهم و خطير يرستارى باشند، تدوين برنامهها

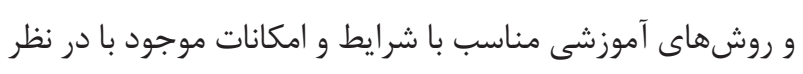

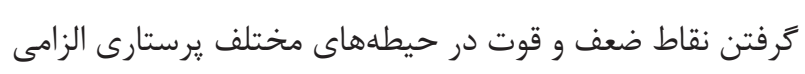

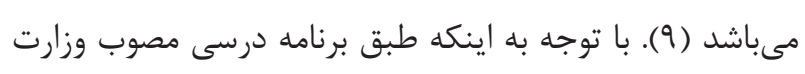

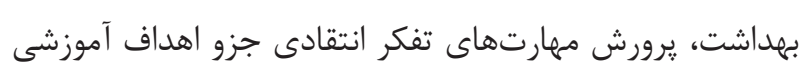

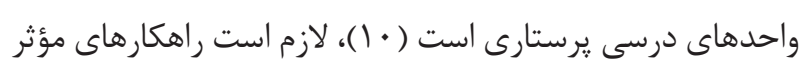

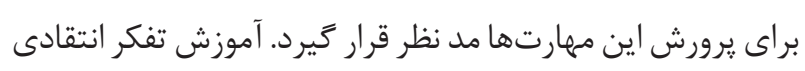

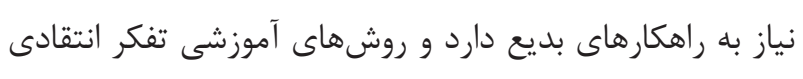

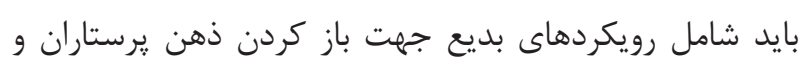

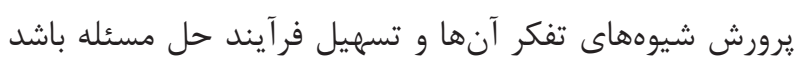
(11). عليرغم به كارگيرى برخى روشهاى نوين آموزشى در دانشكده يرستارى آجا تاكنون تأثير اين روشها بر تفكر انتقادى برى
با توانايى تصميم كيرى مناسب و ممارت تفكر انتقادى بالا مىباشد،

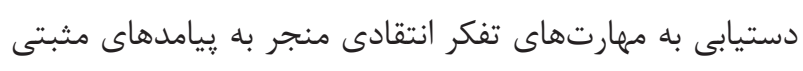

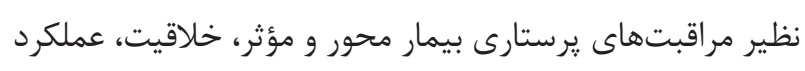

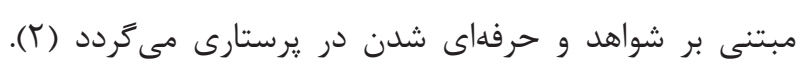

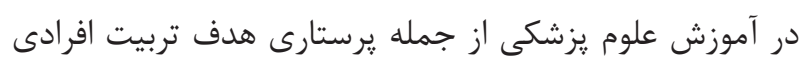

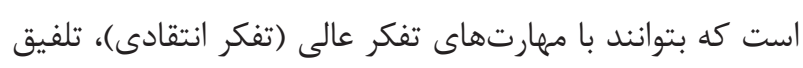

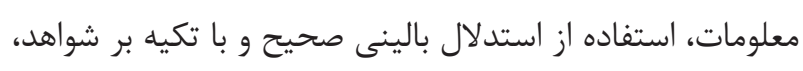
تصميم گيرى را به بهترين نحو انجام دهند (؟).

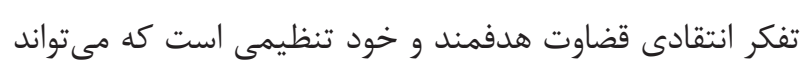

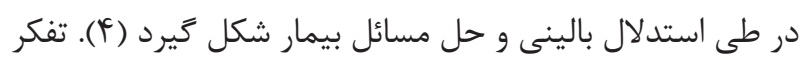

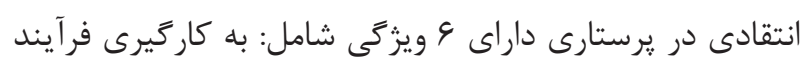

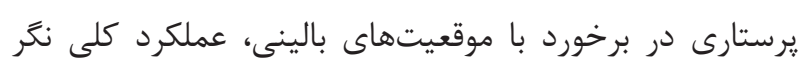

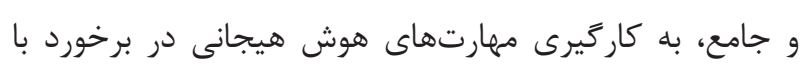

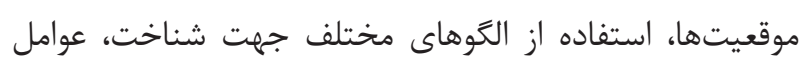

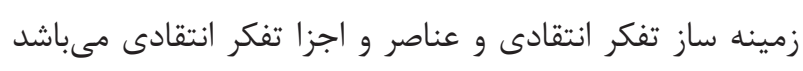

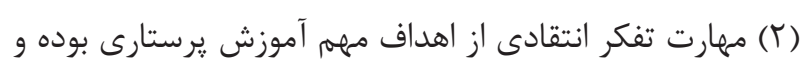

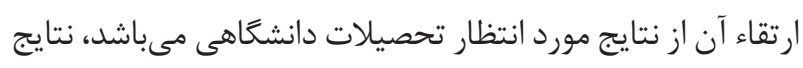
حاصل از مطالعات، مبين بايين بودن نمره تفكر انتقادى يرستاران

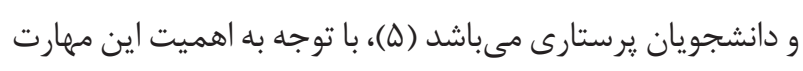

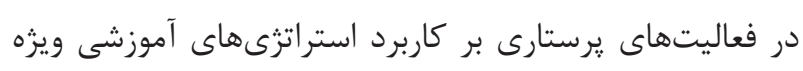

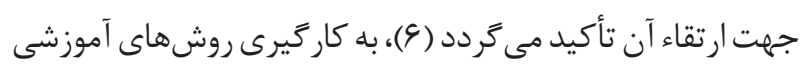

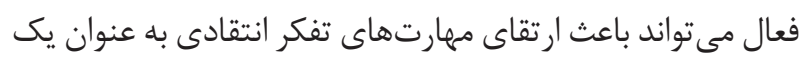

$$
\text { اصل اساسى، در دانشجويان گردد (9). }
$$

استدلال بالينى طى دهdهاى متمادى جزئى اساسى از داز فرآيند

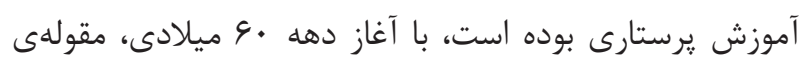

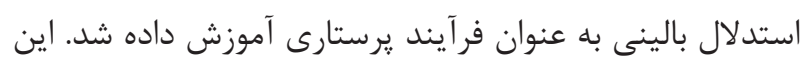

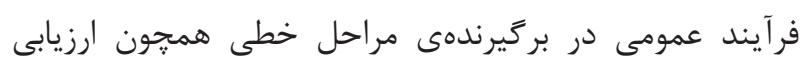

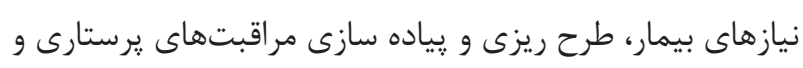

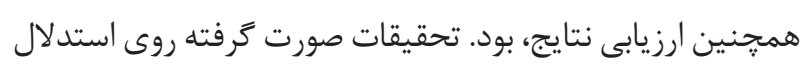

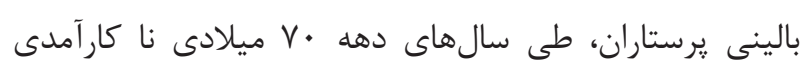

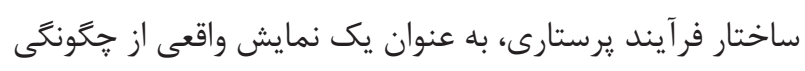
استدلال و قضاوتهاى بالينى يرستاران در دنياى واقعى را آشكار

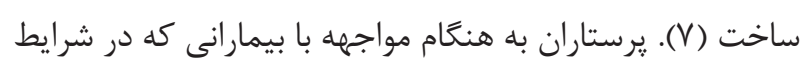

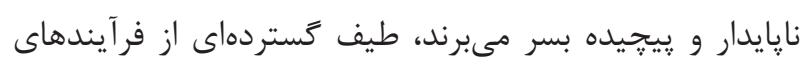




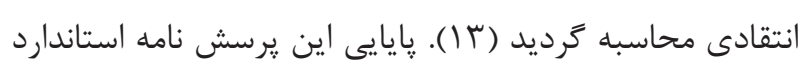

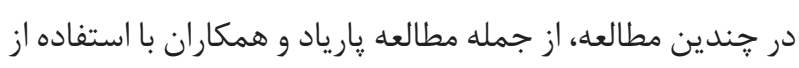
روش همبستكى درونى و از فرمول شماره • r كودر - ريجاردسون تائيد كرديد و ضريب آلفاى كرونباخ (Kuder-Richardson) (Cronbach’s alpha)

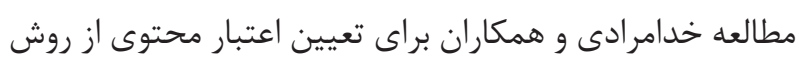

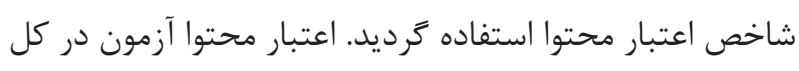

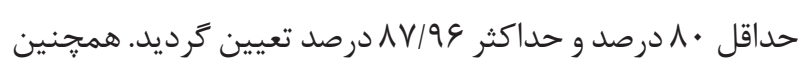

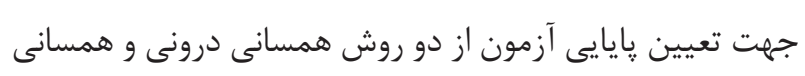

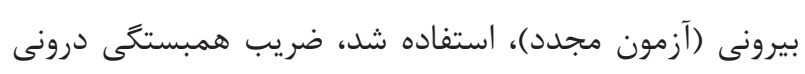

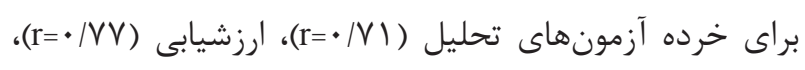

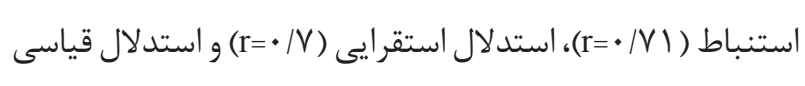

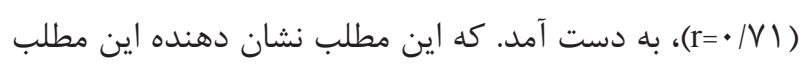

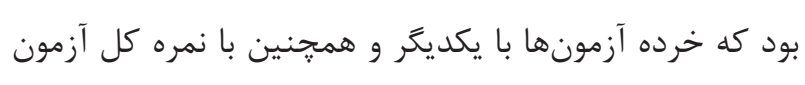

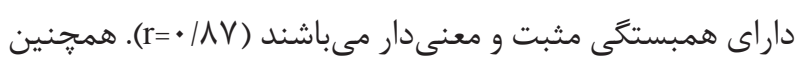

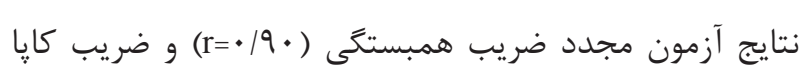

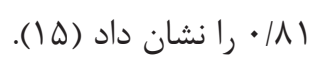

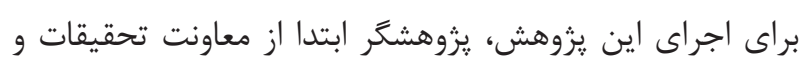

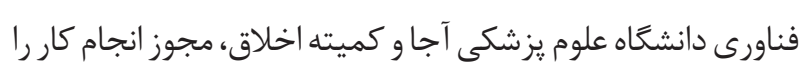

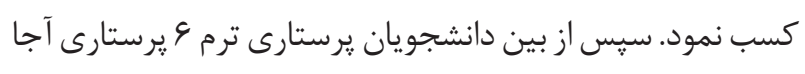

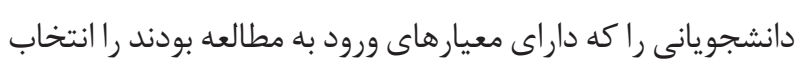

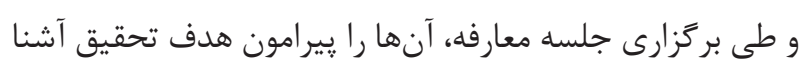

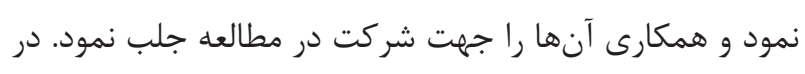

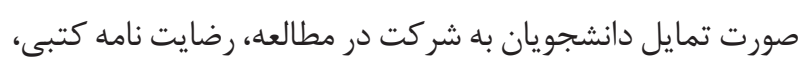

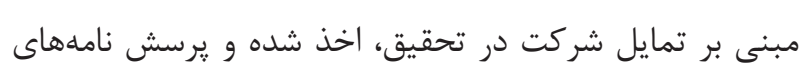
مشخصات فردى، تفكر انتقادى تكميل شد.

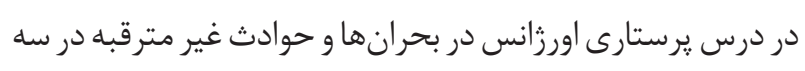

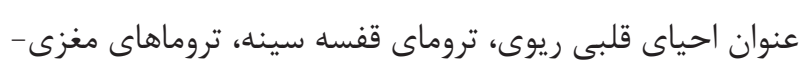

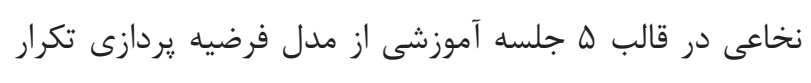

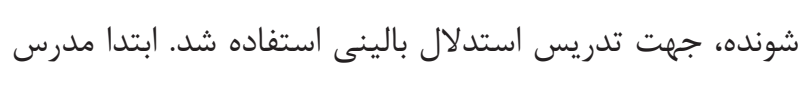
سؤالى را بيان مىنمود و اطلاعاتى محدود در اختيار دانشجويان قرار مىداد. دانشجويان، فرضيههايى مبتنى بر دادههاى حداقلى دانى

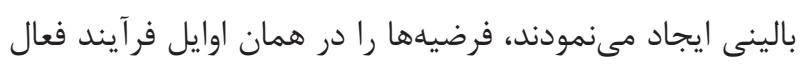

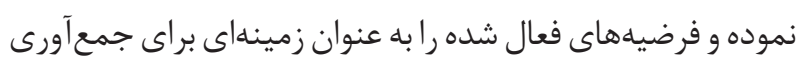

دانشجويان مورد بررسى قرار نكرفته و در مرورى بر مطالعات

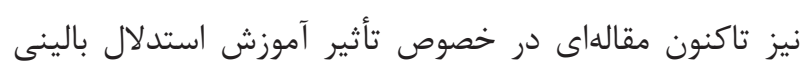
بر تفكر انتقادى دانشجو يافت نشده است. لذا، در اين مقاله به ديه بررسى تأثير آموزش استدلال بالينى بر تفكر انتقادى دانشجويان

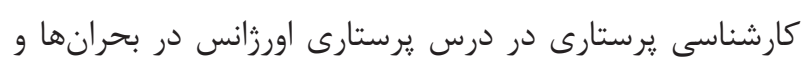
حوادث غيرمترقبه، مى يردازيم.

\section{مواد و روشها - مارها}

مطالعه حاضر، يك مطالعه مقدماتى به شيوه نيمه تجربى از نوع

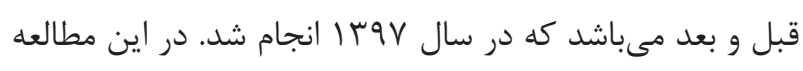

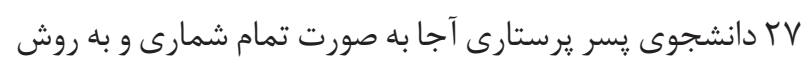

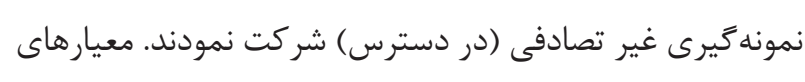

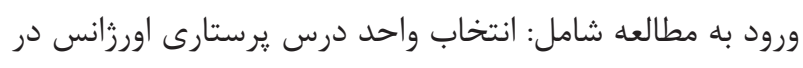
بحرانها و حوادث غير مترقبه در نيمسال اول سال تحصيلى

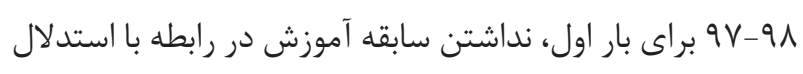
بالينى و تفكر انتقادى و نداشتن سابقه بهيارى قبل از شروع دوره كارشناسى بيوسته يرستارى بود. معيارهاى خروج از مطالعه نيز

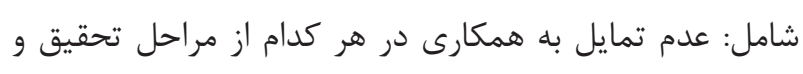

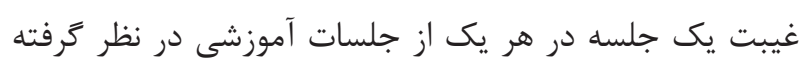

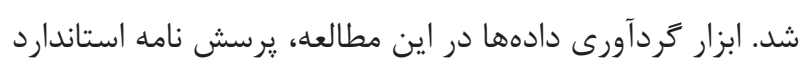

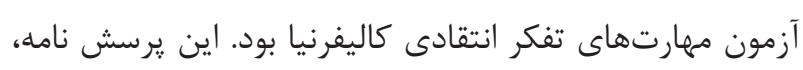

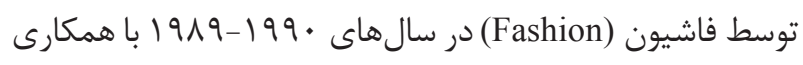

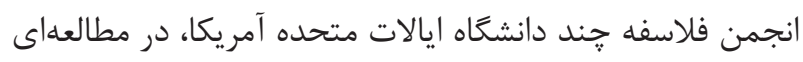

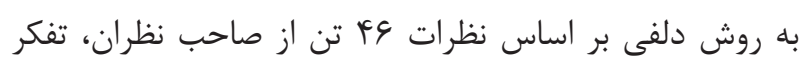

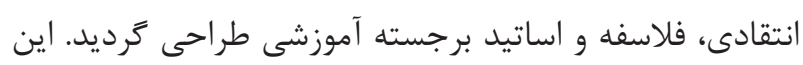

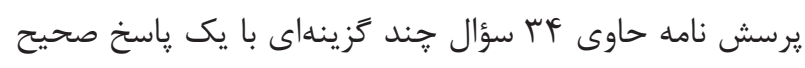

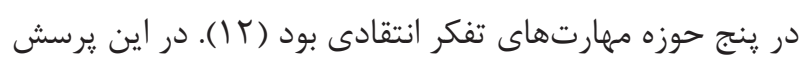

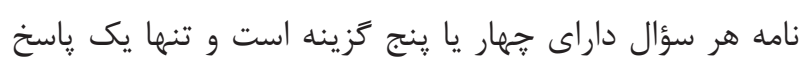

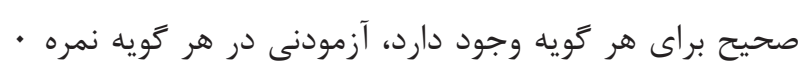

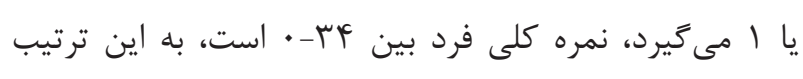

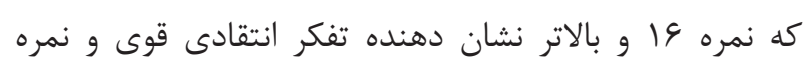
كمتر از 1 انشان دهنده تفكر انتقادى ضعيف است، مدت زمان زمان

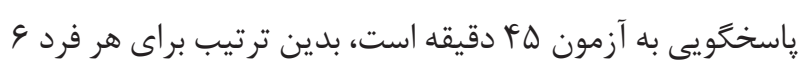

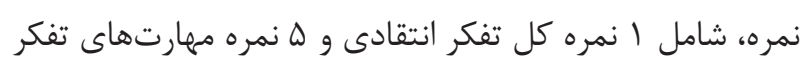


انتقادى قبل و بعد، تفاوت معنادارى (P=PV ) وجود دارد و

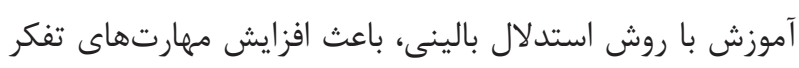
انتقادى به نسبت قبل از مداخله شده است.

\section{بحث و نتيجهَيرى}

اين مطالعه مقدماتى با هدف بررسى تأثير آموزش استدلال بالينى

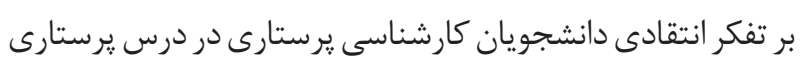

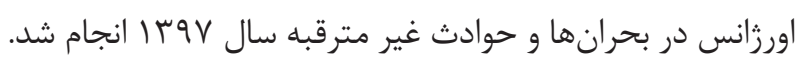

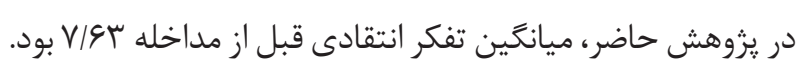

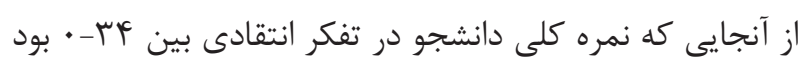

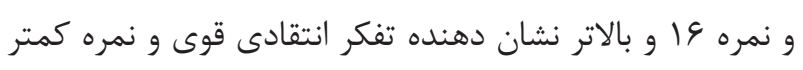

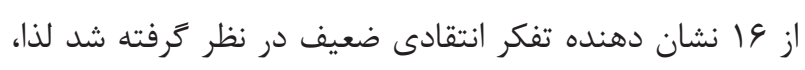

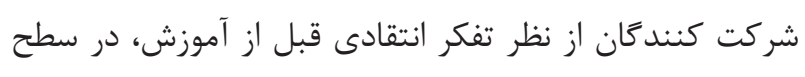

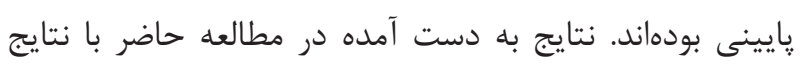
مطالعه آخوندزاده كه مهارتهاى تفكر انتقادى در كل دانشجويان

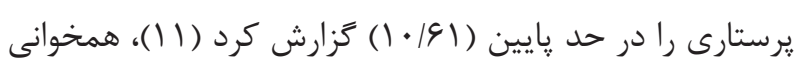
دارد و با مطالعه حسن يور كه مهارتهاى تفكر انتقادى دانشجويان

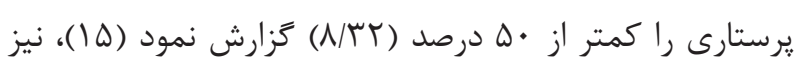

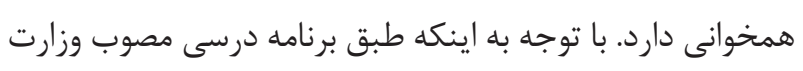

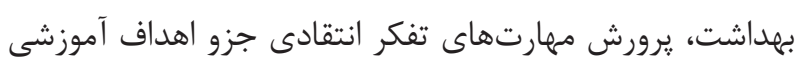

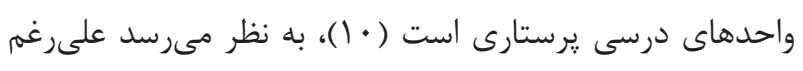
تأكيد بر لزوم ارتقاء تفكر انتقادى دانشجويان در درس سطح آموزش

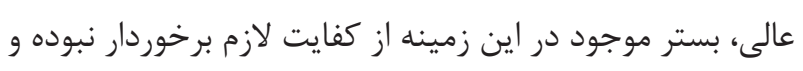

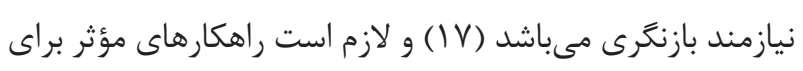
يرورش اين مهارتها مد نظر قرار كيرد. آموزش تفكر انتقادى نياز

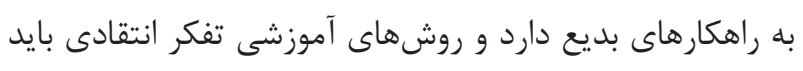

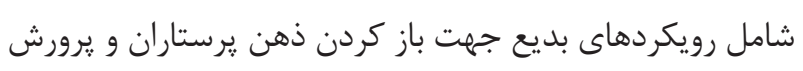

شيوههاى تفكر آنها و تسهيل فرآيند حل مسئله باشد (11).
دادههاى اضافى مرتبط مورد استفاده قرار مى دادند تا بدين ترتيب

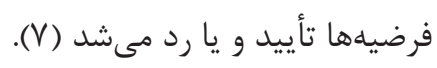

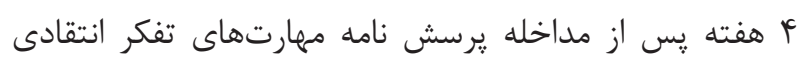

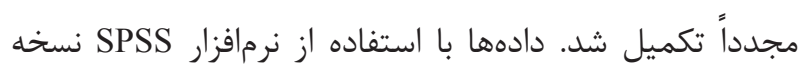

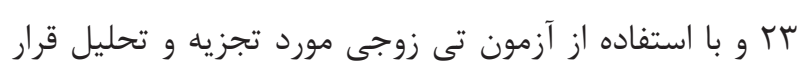
كرفت. اين يزوهش توسط كميته اخلاق در يزوهش دانش دانشعاه

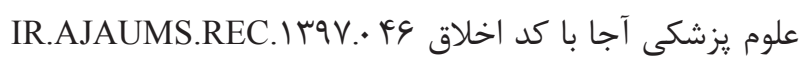

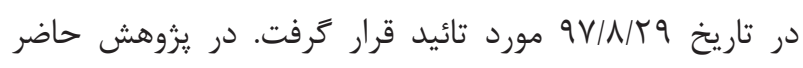

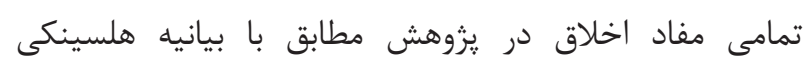
(Declaration Helsinki) يزوهش ابتداى جلسه، براى تمامى واحدهاى يزوهش توضيح

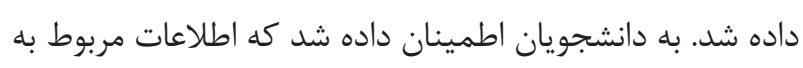

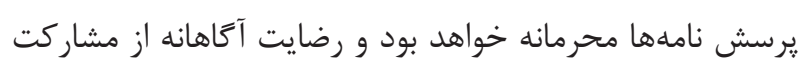

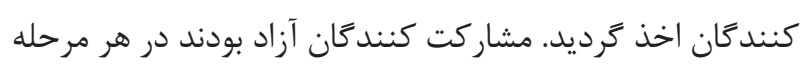

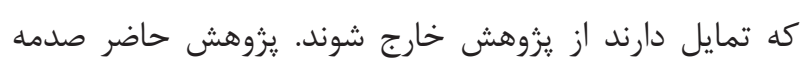

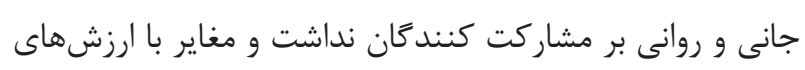

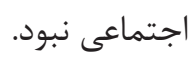

\section{يافتهها}

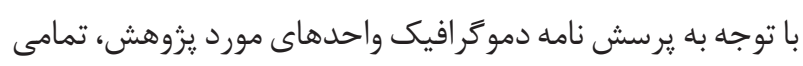

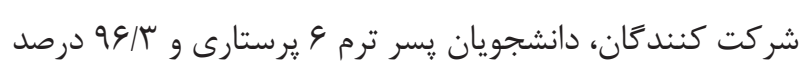

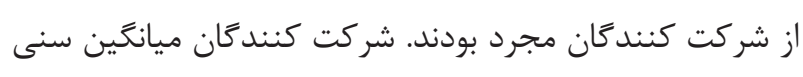

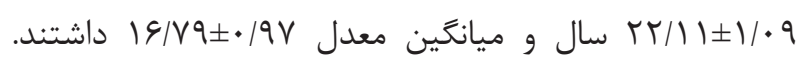
مقايسه ميزان تفكر انتقادى دانشجويان يرستارى در درس يرستارى مئري

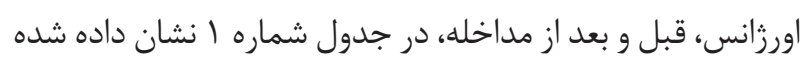

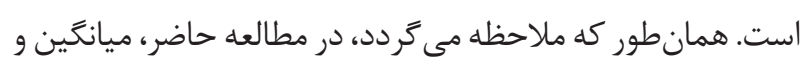

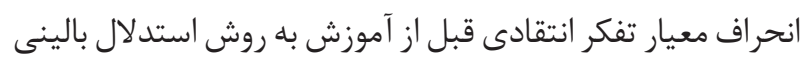

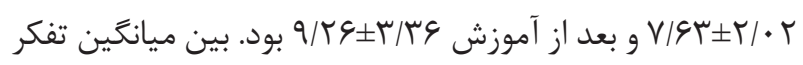

جدول ا- مقايسه ميانغين و انحر اف معيار نمره آزمون تفكر انتقادى دانشجويان، قبل و بعد از آموزش

\begin{tabular}{|c|c|c|c|c|c|}
\hline \multirow{3}{*}{ آزمون تى زوجى } & \multicolumn{4}{|c|}{ زمان } & \multirow{3}{*}{ 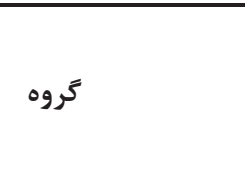 } \\
\hline & \multicolumn{2}{|c|}{ بعد از آموزش } & \multicolumn{2}{|c|}{ قبل از آموزش } & \\
\hline & انحراف معيار & ميانغين & انحراف معيار & ميانَين & \\
\hline $\begin{array}{l}\mathrm{t}=-r / \cdot q \\
\mathrm{P}=. / \cdot \mathrm{FV}\end{array}$ & G & $9 / 49$ & $r / \cdot r$ & $V / \& \Gamma$ & دانشجويان يرستارى \\
\hline
\end{tabular}


من ويتنى U، تفاوت بين دو گروه معنى دار نبود (ه •|P> (P). به

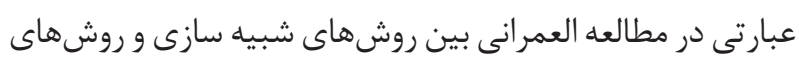
سنتى تفاوت معنى دارى وجود نداشت. در مجموع ميزان تفكر انتقادى دانشجويان يرستارى در درد درست

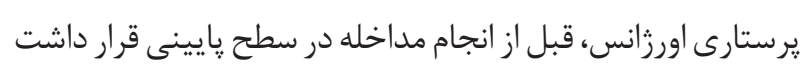

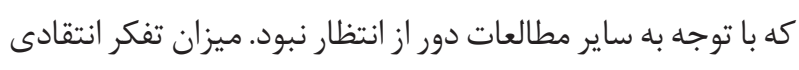
دانشجويان يرستارى، به نسبت قبل از آموزش با روش استدلال

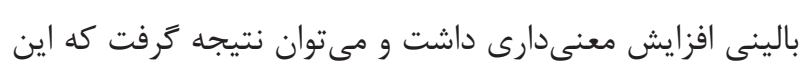
روش آموزشى، هماند ساير روشهاى آموزشى فعال، مىتواند باعث بهبود و ارتقاء تفكر انتقادى در دانشجويان يرستارى گرىدد.

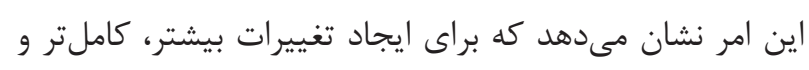

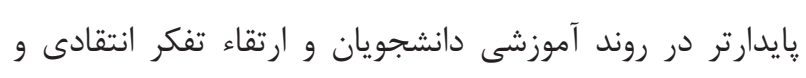

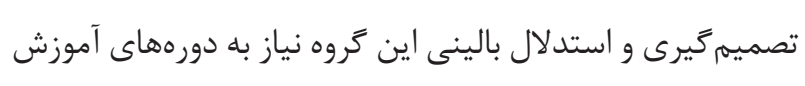
مداوم و هماهنَ شده در سطح دانشكده و حتى دانشعاههاى

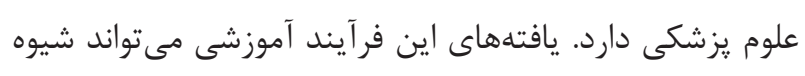

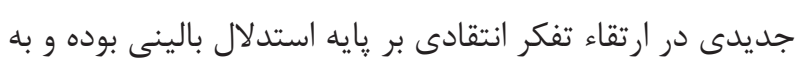
عنوان يك طراحى جديد در آموزش يرستارى مورد استفاده قرار

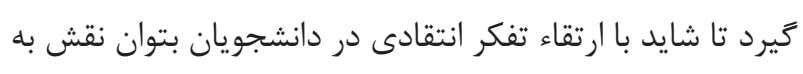
سزايى در تربيت نيروى انسانى كارآمد و متفكر داشت دان.

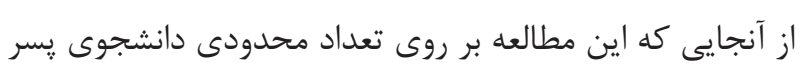

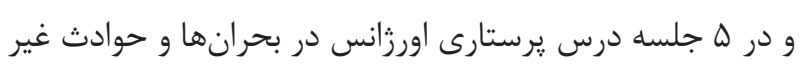

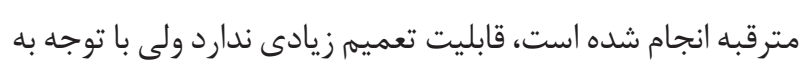

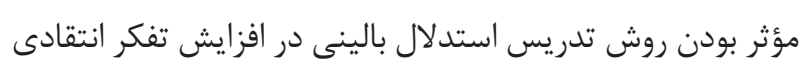

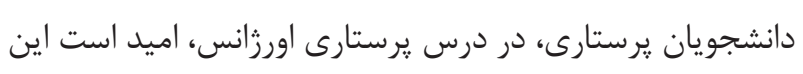

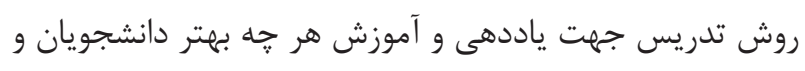

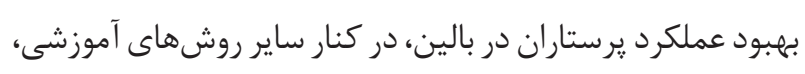

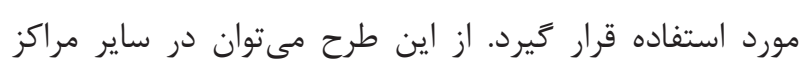

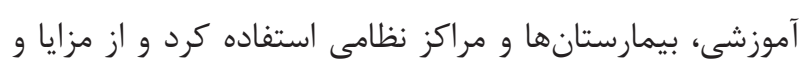

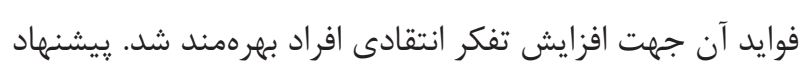
مى گردد، مطالعات مشابه با طرح تحقيق كنترل دار و با جلسات بيشتر بلويزه در بخشهاى بالينى انجام شود.

\section{تشكر و قدردانى} اين مقاله برحَرفته از يايان نامه كارشناسى ارشد يرستارى اورزانس
در اين مطالعه، آموزش با روش استدلال بالينى، باعث افزايش

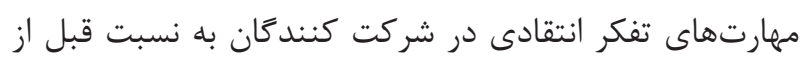

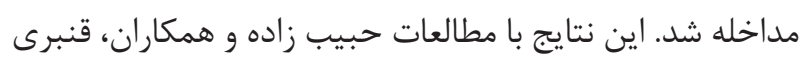
و همكاران، نوحيو همكاران و كادورا و همكاران (Kaddoura)

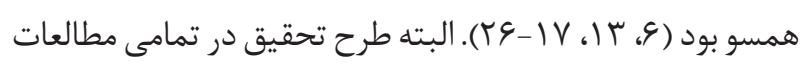
ياد شده به صورت نيمه تجربى بود در حالى كه در مطالعه حاضر نتايج در قالب طرح يك گروهى قبل و بعد ارائه كرديد.

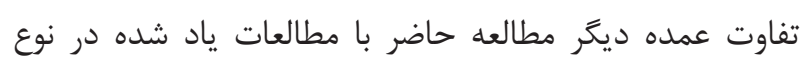

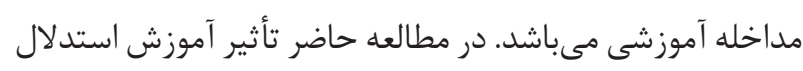

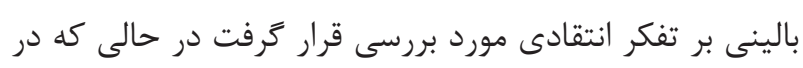

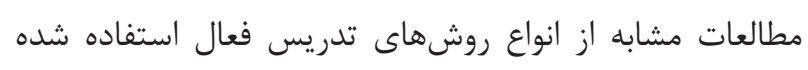

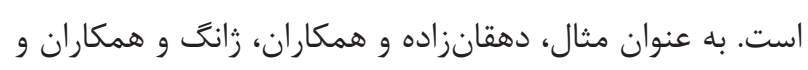

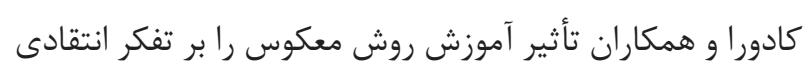

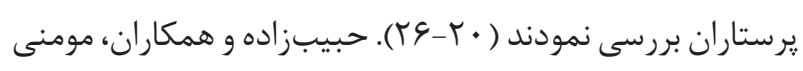

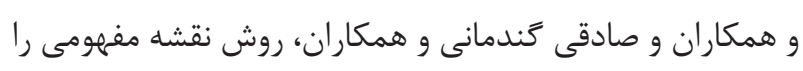

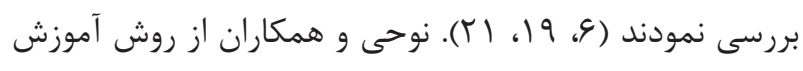

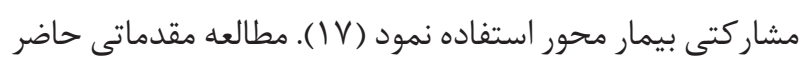

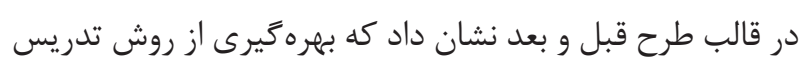

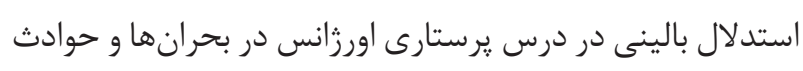

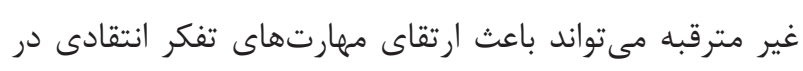

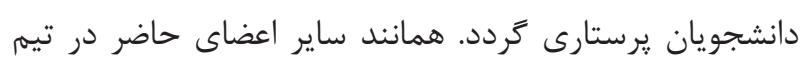
يزشكى، يرستاران نيز در قضاوتهاى اشتراكى مرتبط با فر آيند

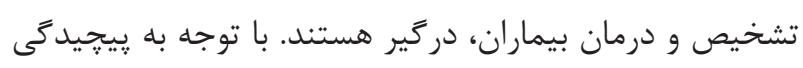

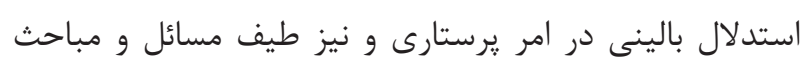

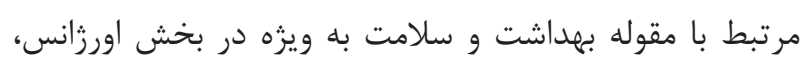
مربيان يرستارى بايستى از روشهاى آموزشى فعال بهره بخيرند

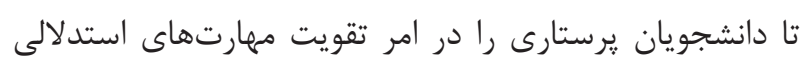
لازم و تفكر انتقادى يارى نمايند. مطالعه حاضر با مطالعه العمرانى (Alamrani) مطابقت ندارد.

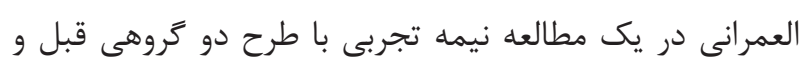

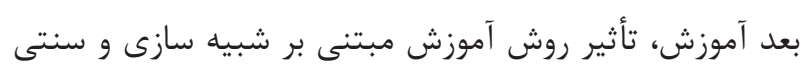

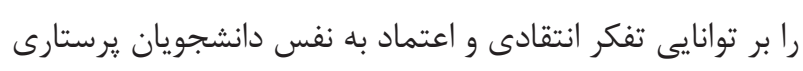

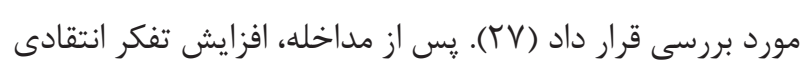

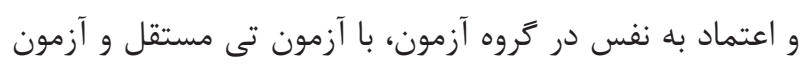




$$
\text { تضاد منافع بن منافعى در خصوص يزوهش حاضر وجود ندارد. }
$$

$$
\begin{aligned}
& \text { مىباشد كه در دانشكده يرستارى دانشگاه علوم يزشكى آجا به }
\end{aligned}
$$

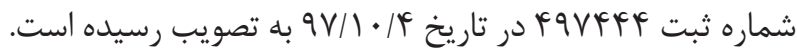

$$
\begin{aligned}
& \text { از كليه دانشجويان و يرسنل دانشكده يرستارى ارتش كه در انجام }
\end{aligned}
$$

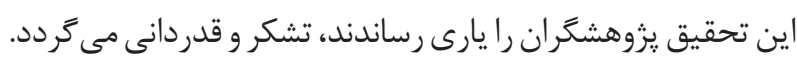

\section{References}

1- Elahi N, Alhani F, Ahmadi F. Challenges to effective teaching, reflection on experience, and perceived nursing: a content analysis. J Qualitative Res Health Sci. 2012;1(3):229-39.

2- Bahmanpour K, Navipour H, Ahmadi F, Kazemnejad A. A concept analysis of critical thinking in clinical nursing. Sci J Kurdistan Univ Med Sci. 2017;22(2).

3- Amini M, Moghadam M, Lotfi F, Kazempour R, Abdolfathi E. Comparison between key feature exam and multiple choice questions in internal medicine department of Shiraz University of medical sciences. Hormozgan Med J. 2013;17(3):265-72.

4- Habibzadeh H, Mohammadpour Y, Khalkhali H, Khajehali N. Effect of evidence-based nursing training on nursing students ability in executive skill of nursing process in Urmia University of Medical Sciences, 2013. J Urmia Nurs \& Midwifery Faculty. 2013;11(4):284-92.

5- Rezaei R, Saatsa S, Sharif Nia SH, Molookzadeh S, Beheshti Z. Evaluation of nursing Students, critical thinking skills in mazandaran university of medical sciences. Biannual J Med Educat Develop Center (edc) Babol Univ Med Sci. 2014;2(1):2934.

6- Habibzadeh H, Rasuli D, Moradi Y. The Effect of Concept Mapping Teaching Method on Critical Thinking Skills of Nursing Students. J Urmia Nurs \& Midwif Faculty. 2014;12(5):379-85.

7- Tanner CA, Lindeman CA. Research in nursing education: assumptions and priorities. J Nurs Educ. 1987;26(2):50-9. www. ncbi.nlm.nih.gov/pubmed/3031242

8- Higgs J, Jones MA, Loftus S, Christensen N. Clinical Reasoning in the Health Professions E-Book: Elsevier Health Sciences; 2008.

9- Hoseinzadeh E, Hamidi Y, Roshanaie G, Cheraghi P, Taghavi M. Evaluation of student satisfaction from Hamadan University of medical sciences educational process and programs in 2012-2011. Pajouhan Scientific J. 2013;11(3):37-44.

10- Aliye S. Iran Nursing Continuing Undergraduate Curriculum: Deputy for Education inistry of Health and Medical Education. 2014

11- Akhoundzadeh K, Ahmari Tehran H, Salehi S, Abedini Z. Critical thinking in nursing education in Iran. Iranian $\mathrm{J}$ Med Educat. 2011;11(3):210-21.

12- Facion P, Facion N. The California critical thinking skills test: form A and form B, test manual. Millbrae: California Academic Press; 1993.

r 13- Ghanbari A, Monfared A, Hoseinzadeh T, Moaddab F, Sedighi A.

The impact of the nursing process education on critical thinking of nursing students. Research in Med Educat. 2017;9(2):25-33. http://dx.doi.org/10.29252/rme.9.2.33

14- Paryad E, Javadi N, Fadakar K, Asiri S. Relationship between critical thinking and clinical decision making in nursing students. Iran J Nursing. 2011;24(73):63-71.

15- Hasanpour M, Hasanzadeh A, Ghaedi Heidari F, Bagheri M. Critical Thinking Skills of Nursing Students. Iran Journal of Nursing. 2015;28(93):22-31. http://dx.doi.org/10.29252/ ijn.28.93.94.22

16- Mobasher M, Mahdaviniya J, Zendehdel K. ethics, medical research, Helsinki Declaration, informed consent. Iranian J Med Ethics and History of Medicine. 2012;5(1):62-8.

17- Noohi E, Abaszadeh A. Effect of patient-centered collaborative learning on students' scores of the nursing process and critical thinking of nursing trainers. J Medical Educat \& Develop. 2013;8(3):53-62.

18- Adib-Hajbaghery M, Sharifi N. Effect of simulation training on the development of nurses and nursing students' critical thinking: A systematic literature review. Nurse Educ Today. 2017;50:17-24. http://dx.doi.org/10.1016/j.nedt.2016.12.011 www.ncbi.nlm.nih. gov/pubmed/28011333

19- Momeni H, Salehi A, Sadeghi H. Comparing the Effect of Problem Based Learning and Concept Mapping on Critical Thinking Disposition of Nursing Student. Educat Strategies in Med Sci. 2017;10(4):234-44.

20- Dehghanzadeh S, Jafaraghaie F, Khordadi Astane H. The Effect of Flipped Classroom On Critical Thinking Disposition in Nursing Students. Iranian J Med Educat. 2018;18:39-48.

21- Sadeghi-Gandomani H, Delaram M, Naseri-Brugeni N. Comparison of concept mapping and conventional teaching methods on creativity of nursing students. J Med Educat \& Develop. 2014;9(3):48-57.

22- Shabouni Z, Nouhi E, Okhovati M. The Effect of Team-Based Learning in Medical Information Systems Course on Academic Achievement in Postgraduate Students of Kerman University of Medical Sciences, Iran. sdmej. 2016;13(1).

23- Raoufi S, Farhadi A, Sheikhian A. Impact of the team effectiveness design of teaching on critical thinking, self-confidence and learning of nursing students. J Med Educat \& Develop. 2014;9(2):23-32.

24- Zhang C, Fan H, Xia J, Guo H, Jiang X, Yan Y. The Effects of Reflective Training on the Disposition of Critical Thinking 
for Nursing Students in China: A Controlled Trial. Asian Nurs Res (Korean Soc Nurs Sci). 2017;11(3):194-200. http:// dx.doi.org/10.1016/j.anr.2017.07.002 www.ncbi.nlm.nih.gov/ pubmed/28991600

25- Hong S, Yu P. Comparison of the effectiveness of two styles of case-based learning implemented in lectures for developing nursing students' critical thinking ability: A randomized controlled trial. Int J Nurs Stud. 2017;68:16-24. http://dx.doi.org/10.1016/j. ijnurstu.2016.12.008 www.ncbi.nlm.nih.gov/pubmed/28043015

26- Kaddoura M, Van-Dyke O, Yang Q. Impact of a concept map teaching approach on nursing students' critical thinking skills. Nurs Health Sci. 2016;18(3):350-4. http://dx.doi.org/10.1111/ nhs.12277 www.ncbi.nlm.nih.gov/pubmed/26891960

27- Alamrani MH, Alammar KA, Alqahtani SS, Salem OA. Comparing the Effects of Simulation-Based and Traditional Teaching Methods on the Critical Thinking Abilities and SelfConfidence of Nursing Students. J Nurs Res. 2018;26(3):152-7. http://dx.doi.org/10.1097/jnr.0000000000000231 www.ncbi.nlm. nih.gov/pubmed/29016466 